\title{
ESTIMATIVA DA DEMANDA DE ÁGUA NAS ÁREAS IRRIGADAS DA BACIA DO RIO PARACATU ${ }^{1}$
}

\author{
RENATA DEL G. RODRIGUEZ ${ }^{2}$, FERNANDO F. PRUSKI ${ }^{3}$, \\ LUCIANO F. DE NOVAES ${ }^{4}$, MÁRCIO M. RAMOS ${ }^{5}$, DEMETRIUS D. DA SILVA ${ }^{6}$, \\ ALESSANDRO DE F. TEIXEIRA ${ }^{7}$
}

\begin{abstract}
RESUMO: A irrigação apresentou expressivo crescimento na bacia do Paracatu na década de 1970, sendo que, como consequiência da grande expansão da agricultura irrigada, sérios conflitos têm surgido em várias partes da bacia. Tendo em vista esses conflitos, o presente trabalho teve como objetivo analisar a demanda de água pela irrigação e sua sazonalidade para as condições climáticas da bacia do Paracatu. A demanda de água pela irrigação foi realizada com base nas condições climáticas e nas áreas irrigadas de cada cultura, sendo essas obtidas com base nos dados do censo agropecuário do Instituto Brasileiro de Geografia e Estatística. A vazão média anual retirada pela irrigação na bacia do Paracatu, em 1996, foi de $0,15 \mathrm{~L} \mathrm{~s}^{-1} \mathrm{ha}^{-1}$, sendo a vazão média retirada no mês de maior demanda de $0,34 \mathrm{~L} \mathrm{~s}^{-1} \mathrm{ha}^{-1}$. A quantidade média de água necessária para atender à demanda das culturas irrigadas na bacia do Paracatu foi de $0,35 \mathrm{~L} \mathrm{~s}^{-1} \mathrm{ha}^{-1}$, sendo o valor correspondente ao mês de maior demanda evapotranspirométrica de $0,50 \mathrm{~L} \mathrm{~s}^{-1} \mathrm{ha}^{-1}$.
\end{abstract}

PALAVRAS-CHAVE: evapotranspiração, precipitação efetiva, vazão retirada pela irrigação.

\section{WATER DEMAND BY IRRIGATION IN PARACATU BASIN}

\begin{abstract}
Serious conflicts have occurred among the water sectors in the Paracatu Basin as a consequence of the intense growth of irrigation used in the 70's. The main objective of this paper was to analyze the water demand by irrigation in the Paracatu Basin considering the climatic changes observed during the year. The water demand by irrigation was calculated considering the climatic conditions of the region and the irrigated areas corresponding to each crop, which were obtained from the agricultural census made by the Brazilian Institute of Geography and Statistics. The annual average water withdrawal by irrigation in the Paracatu Basin conditions was $0.15 \mathrm{~L} \mathrm{~s}^{-1} \mathrm{ha}^{-1}$ while the water withdrawal in the month with the maximum demand was $0.34 \mathrm{~L} \mathrm{~s}^{-1} \mathrm{ha}^{-1}$. The water amount necessary to assist the demand of the irrigated crops in the Paracatu Basin was $0.35 \mathrm{~L} \mathrm{~s}^{-1} \mathrm{ha}^{-1}$ for the average and $0.50 \mathrm{~L} \mathrm{~s}^{-1} \mathrm{ha}^{-1}$ for the month with the maximum demand.
\end{abstract}

KEYWORDS: evapotranspiration, effective rainfall, water withdrawals by irrigation.

\footnotetext{
${ }^{1}$ Extraído da dissertação de mestrado do primeiro autor e financiado pela FAPEMIG.

${ }^{2}$ Eng $^{\text {a }}$ Agrônoma, Estudante de Doutorado, Departamento de Engenharia Agrícola, UFV, Viçosa - MG, Fone: (0XX31)3899.3469, rdgrodriguez@gprh.ufv.br

${ }^{3}$ Eng $^{\circ}$ Agrícola, Prof. Titular, Departamento de Engenharia Agrícola, UFV, Viçosa - MG.

${ }^{4}$ Eng $^{\mathrm{o}}$ Civil, Estudante de Mestrado, Departamento de Engenharia Agrícola, UFV, Viçosa - MG.

${ }^{5}$ Engo Agrônomo, Prof. Titular, Departamento de Engenharia Agrícola, UFV, Viçosa - MG.

${ }^{6}$ Eng ${ }^{\circ}$ Agrícola, Prof. Adjunto, Departamento de Engenharia Agrícola, UFV, Viçosa - MG.

${ }^{7}$ Bacharel em Informática, Cientec, Viçosa - MG.

Recebido pelo Conselho Editorial em: 20-2-2005
}

Aprovado pelo Conselho Editorial em: 12-2-2007 


\section{INTRODUÇÃO}

A principal utilização da água ocorre na irrigação, sendo essa responsável por cerca de $70 \%$ do total consumido no mundo (UNESCO, 2003) e por $64,7 \%$ do consumo de água no Brasil (TUCCI et al., 2001). Na bacia do São Francisco, a irrigação é responsável, segundo ANA (2002), por $71,4 \%\left(160 \mathrm{~m}^{3} \mathrm{~s}^{-1}\right)$ da demanda total de água na bacia.

O Rio Paracatu, situado no médio São Francisco, é o afluente com maior contribuição (20,8\%) para a formação da vazão do Rio São Francisco (PEREIRA, 2004), drenando aproximadamente $45.600 \mathrm{~km}^{2}$ (BRASIL, 1996).

A irrigação apresentou expressivo crescimento na bacia do Paracatu, principalmente após incentivos advindos de programas governamentais iniciados na década de 1970, como o Plano de Desenvolvimento Integrado do Noroeste Mineiro (PLANOROESTE). O principal usuário da água também é a irrigação, que ocupa 37.150 ha. O sistema de irrigação predominante é o pivô central (88\%), e em 42\% (13.600 ha) dessa bacia já ocorrem limitações quanto ao uso da água (BRASIL, 1996). Como conseqüência dessa grande expansão da agricultura irrigada, sérios conflitos têm surgido em várias partes da bacia, principalmente nas sub-bacias do Ribeirão Entre Ribeiros e do Rio Preto.

Estudos realizados pela Secretaria de Agricultura e Abastecimento do Distrito Federal indicam que o uso dos recursos hídricos para a irrigação já havia, em 1995, superado a disponibilidade hídrica em alguns rios da sub-bacia do Rio Preto (FERREIRA \& ARAÚJO NETO, 2004).

Tendo em vista os conflitos pelo uso da água na bacia do Paracatu, ocasionados principalmente pela irrigação, o presente trabalho teve como objetivo analisar a demanda de água pela irrigação e sua sazonalidade para as condições climáticas da bacia do Paracatu.

\section{MATERIAL E MÉTODOS}

As vazões de retirada pela irrigação foram estimadas para o Distrito Federal e para cada um dos 21 municípios pertencentes à bacia do Paracatu, tendo sido a vazão de retirada pela irrigação na bacia do Paracatu obtida pelo somatório das vazões relativas a todos os municípios pertencentes à bacia.

Para o cálculo da vazão de retirada pela irrigação, foi considerado o critério de proporcionalidade da área do município localizada na área de drenagem considerada. Na Tabela 1, estão apresentados os municípios pertencentes à bacia do Paracatu, suas respectivas áreas e a percentagem dessas dentro da bacia.

A vazão de retirada pela irrigação foi estimada com base na irrigação total necessária e na área irrigada de cada cultura, em cada mês no município, sendo determinada pela eq. (1).

$$
Q_{r}=\sum_{i=1}^{c n}\left[\frac{E T_{r c}-P_{e}}{E_{a}}\right] A_{m, i, c, m} 10.000
$$

em que,

$\mathrm{Q}_{\mathrm{r}}$ - vazão de retirada pela irrigação no município, $\mathrm{L} \mathrm{d}^{-1}$;

$\mathrm{ET}_{\mathrm{rc}}$ - evapotranspiração real da cultura em cada mês no município, $\mathrm{mm} \mathrm{d}^{-1}$;

$\mathrm{P}_{\mathrm{e}}$ - precipitação efetiva mensal no município, $\mathrm{mm} \mathrm{d}^{-1}$;

$\mathrm{E}_{\mathrm{a}}$ - eficiência de aplicação, adimensional;

$\mathrm{A}_{\mathrm{m}, \mathrm{i}, \mathrm{c}, \mathrm{m}}$ - área irrigada da cultura no município em cada mês, ha; e

cn - número de culturas irrigadas no município.

$\mathrm{m}$ - município;

i - cultura irrigada;

c - cultura, e

me - mês. 
TABELA 1. Municípios pertencentes à bacia do Paracatu, suas respectivas áreas e a percentagens dessas dentro da bacia.

\begin{tabular}{cccc}
\hline \multirow{2}{*}{ Estado } & Municípios & $\begin{array}{c}\text { Área do Município } \\
\left(\mathrm{km}^{2}\right)\end{array}$ & $\begin{array}{c}\text { \% da Área do Município } \\
\text { Pertencente à Bacia }\end{array}$ \\
\hline \multirow{4}{*}{ Bonfinópolis de Minas } & 1.778 & 9,2 \\
Brasilândia de Minas & 7.226 & 96,9 \\
Buritizeiro & 2.515 & 47,5 \\
& Cabeceira Grande & 1.026 & 100,0 \\
& Dom Bosco & 8.22 & 98,9 \\
Guarda Mor & 2.066 & 56,0 \\
& João Pinheiro & 10.717 & 100,0 \\
& Lagamar & 1.473 & 77,9 \\
& Lagoa Grande & 1.220 & 100,0 \\
& Natalândia & 471 & 100,0 \\
& Paracatu & 8.232 & 77,0 \\
& Patos de Minas & 3.189 & 2,6 \\
& Presidente Olegário & 3.531 & 85,7 \\
& Santa Fé de Minas & 2.917 & 77,7 \\
& São Gonçalo do Abaeté & 2.687 & 0,6 \\
& Unaí & 8.464 & 64,7 \\
& Varjão de Minas & 653 & 4,0 \\
& Vazante & 1.903 & 100,0 \\
\hline GO & Cabeceiras & 1.128 & 50,4 \\
& Cristalina & 6.161 & 5,4 \\
& Formosa & 5.807 & 21,4 \\
\hline & Distrito Federal & 5.802 & 22,9 \\
\hline
\end{tabular}

A evapotranspiração real mensal de cada cultura foi estimada com base na evapotranspiração potencial da cultura de referência, calculada pelo método de Penman-Monteith, nos coeficientes das culturas $\left(\mathrm{K}_{\mathrm{c}}\right)$ e no coeficiente que depende da umidade do solo $\left(\mathrm{K}_{\mathrm{s}}\right)$. Os coeficientes de cultura em cada estágio de desenvolvimento das culturas foram obtidos na publicação da FAO 56 (ALLEN et al., 1998). As culturas irrigadas predominantes na bacia, em 1996 (último ano de censo), foram a soja ( $44 \%$ do total irrigado) e o milho ( $33 \%$ do total irrigado).

Para cada cultura, foi associado o método de irrigação de uso mais freqüente, sendo o método de irrigação por aspersão associado às culturas temporárias e o de irrigação localizada às culturas permanentes. Adotaram-se os valores de 0,81 e 0,88 para $K_{s}$ e de 0,70 e 0,79 para $E_{a}$ nas irrigações por aspersão e localizada, respectivamente, com base nos resultados obtidos por RAMOS \& PRUSKI (2003), os quais obtiveram os valores de $\mathrm{K}_{\mathrm{s}}$ e $\mathrm{E}_{\mathrm{a}}$ por meio da avaliação de 55 projetos de irrigação (33 de irrigação localizada e 22 por aspersão) situados no Vale do São Francisco, sendo utilizado para a quantificação dessas variáveis o procedimento descrito por BERNARDO et al. (2005).

A precipitação efetiva foi obtida pelo método proposto pelo boletim 24 da FAO (DOORENBOS \& PRUITT, 1977). Esse método estima a precipitação efetiva média mensal em função dos valores da precipitação média mensal, da evapotranspiração potencial mensal da cultura e da capacidade total de água no solo.

Em virtude da ausência de dados censitários referentes à área irrigada de cada cultura em cada mês no município, necessitou-se proceder à sua estimativa a partir das informações existentes. Para esse propósito, foi necessário estimar um valor inicial da área irrigada para cada cultura no município, sendo esse valor posteriormente corrigido pela multiplicação por um fator de correção que permitiu que a soma das áreas irrigadas para cada cultura fosse igual à área irrigada total do município (apresentada nos censos agropecuários do IBGE, 1996). 
A área irrigada de cada cultura e em cada ano no município foi estimada pela eq.(2).

$$
\mathrm{A}_{\mathrm{m}, \mathrm{i}, \mathrm{c}, \mathrm{a}}=\mathrm{A}_{\mathrm{m}, \mathrm{i}, \mathrm{c}, \mathrm{a}, \mathrm{vi}} \mathrm{fc}
$$

em que,

$\mathrm{A}_{\mathrm{m}, \mathrm{i}, \mathrm{c}, \mathrm{a}}$ - área irrigada da cultura em cada ano no município, ha;

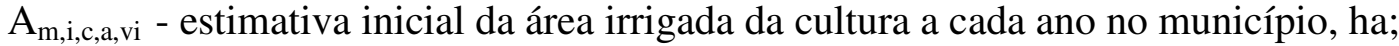

fc - fator de correção da área irrigada no município, adimensional;

a - ano, e

vi - valor inicial.

A estimativa inicial da área irrigada de cada cultura e cada ano no município foi feita pela eq.(3).

$$
\mathrm{A}_{\mathrm{m}, \mathrm{i}, \mathrm{c}, \mathrm{a}, \mathrm{vi}}=\frac{\mathrm{A}_{\mathrm{e}, \mathrm{i}, \mathrm{c}, \mathrm{a}}}{\mathrm{A}_{\mathrm{e}, \mathrm{c}, \mathrm{c}, \mathrm{a}}} \mathrm{A}_{\mathrm{m}, \mathrm{c}, \mathrm{c}, \mathrm{a}}
$$

em que,

$\mathrm{A}_{\mathrm{e}, \mathrm{i}, \mathrm{c}, \mathrm{a}}$ - área irrigada da cultura em cada ano no Estado, ha (obtida nos censos agropecuários do IBGE, 1996);

$\mathrm{A}_{\mathrm{e}, \mathrm{c}, \mathrm{c}, \mathrm{a}}$ - área colhida da cultura em cada ano no Estado, ha (obtida nos censos agropecuários do IBGE, 1996);

$\mathrm{A}_{\mathrm{m}, \mathrm{c}, \mathrm{c}, \mathrm{a}}$ - área colhida da cultura em cada ano no município, ha (obtida nos censos agropecuários do IBGE, 1996);

e - Estado, e

co - cultura colhida.

O fator de correção foi determinado pela eq.(4).

$$
\mathrm{fc}=\frac{\mathrm{A}_{\mathrm{m}, \mathrm{i}, \mathrm{t}, \mathrm{a}}}{\sum_{\mathrm{i}=1}^{\mathrm{cn}} \mathrm{A}_{\mathrm{m}, \mathrm{i}, \mathrm{c}, \mathrm{a}, \mathrm{vi}}}
$$

em que,

$\mathrm{A}_{\mathrm{m}, \mathrm{i}, \mathrm{t}, \mathrm{a}}$ - área total irrigada no município no ano, ha (obtida nos censos agropecuários do IBGE, 1996).

Para as culturas permanentes, a área irrigada da cultura em cada ano no município foi mantida constante em cada mês; entretanto, para as culturas temporárias, foi necessária a estimativa da área irrigada de cada cultura em cada mês no município.

Em virtude da ausência de dados censitários referentes à área colhida de cada cultura, em cada mês no município e no censo, essa área foi determinada pela eq.(5).

$$
\mathrm{A}_{\mathrm{m}, \mathrm{c}, \mathrm{c}, \mathrm{m}}=\mathrm{A}_{\mathrm{m}, \mathrm{c}, \mathrm{c}, \mathrm{a}} \mathrm{fc}_{\mathrm{e}, \mathrm{c}, \mathrm{c}, \mathrm{m}_{\mathrm{i}}}
$$

em que,

$\mathrm{A}_{\mathrm{m}, \mathrm{c}, \mathrm{c}, \mathrm{m}}$ - área colhida da cultura em determinado mês no município, ha (obtida nos censos agropecuários do IBGE), e

$\mathrm{fc}_{\mathrm{e}, \mathrm{c}, \mathrm{c}, \mathrm{mi}}$ - fator de correção da área colhida da cultura no mês i no Estado.

O fator de correção da área colhida da cultura do mês i no Estado foi estimado pela eq.(6).

$$
\mathrm{fc}_{\mathrm{e}, \mathrm{c}, \mathrm{c}, \mathrm{m}_{\mathrm{i}}}=\frac{\mathrm{A}_{\mathrm{e}, \mathrm{c}, \mathrm{c}, \mathrm{mi}}}{\mathrm{A}_{\mathrm{e}, \mathrm{c}, \mathrm{c}, \mathrm{a}}}
$$

em que,

$\mathrm{A}_{\mathrm{e}, \mathrm{c}, \mathrm{c}, \mathrm{mi}}$ - área colhida da cultura do mês i no Estado, ha (obtida nos censos agropecuários do IBGE). 
A fim de caracterizar a distribuição da área irrigada no transcorrer do ano, somaram-se, da menor para a maior, as áreas colhidas da cultura, em cada mês, no município até a obtenção da área total irrigada da cultura por ano no município. As áreas colhidas que não foram computadas para a obtenção da área total irrigada foram consideradas áreas onde não ocorreu irrigação.

Depois de obtidas as áreas irrigadas por mês da cultura no município, procedeu-se à defasagem correspondente ao ciclo da cultura, visando à obtenção da data de plantio, a partir da qual se fez o cálculo de vazão requerida pela irrigação.

A vazão de água necessária para atender à demanda das culturas irrigadas corresponde à contribuição associada à precipitação efetiva, a qual foi obtida pela eq.(7).

$$
\mathrm{Q}_{\mathrm{ef}}=\frac{\mathrm{P}_{\mathrm{e}}}{8,6}
$$

em que,

$\mathrm{Q}_{\mathrm{ef}}$ - vazão de água necessária para atender à demanda das culturas irrigadas, $\mathrm{L} \mathrm{s}^{-1} \mathrm{ha}^{-1}$.

\section{RESULTADOS E DISCUSSÃO}

Na Figura 1, representam-se as vazões médias mensais consumidas pela irrigação e a vazão média anual consumida por esse segmento na bacia do Paracatu, no período de 1970 a 1996, uma vez que 1996 foi o último ano em que houve realização do censo agropecuário. As grandes variações das vazões médias mensais retiradas pela irrigação são decorrentes das expressivas mudanças das variáveis climáticas que interferem diretamente na disponibilidade natural de água para as culturas ao longo do tempo, visto que a bacia apresenta, segundo a classificação de Köeppen, clima tropical chuvoso típico, com chuvas concentradas na primavera e no verão (outubro a fevereiro), sendo a estação seca bem definida e evidenciada no período de junho a setembro.

A vazão média anual retirada pela irrigação apresenta acentuada tendência de crescimento, sendo o comportamento dessa variável determinado, principalmente, pelo crescimento da área irrigada no período de análise. De 1970 a 1996, a vazão média anual retirada pela irrigação na bacia teve crescimento de 62 vezes, enquanto a área irrigada teve aumento de 73 vezes.

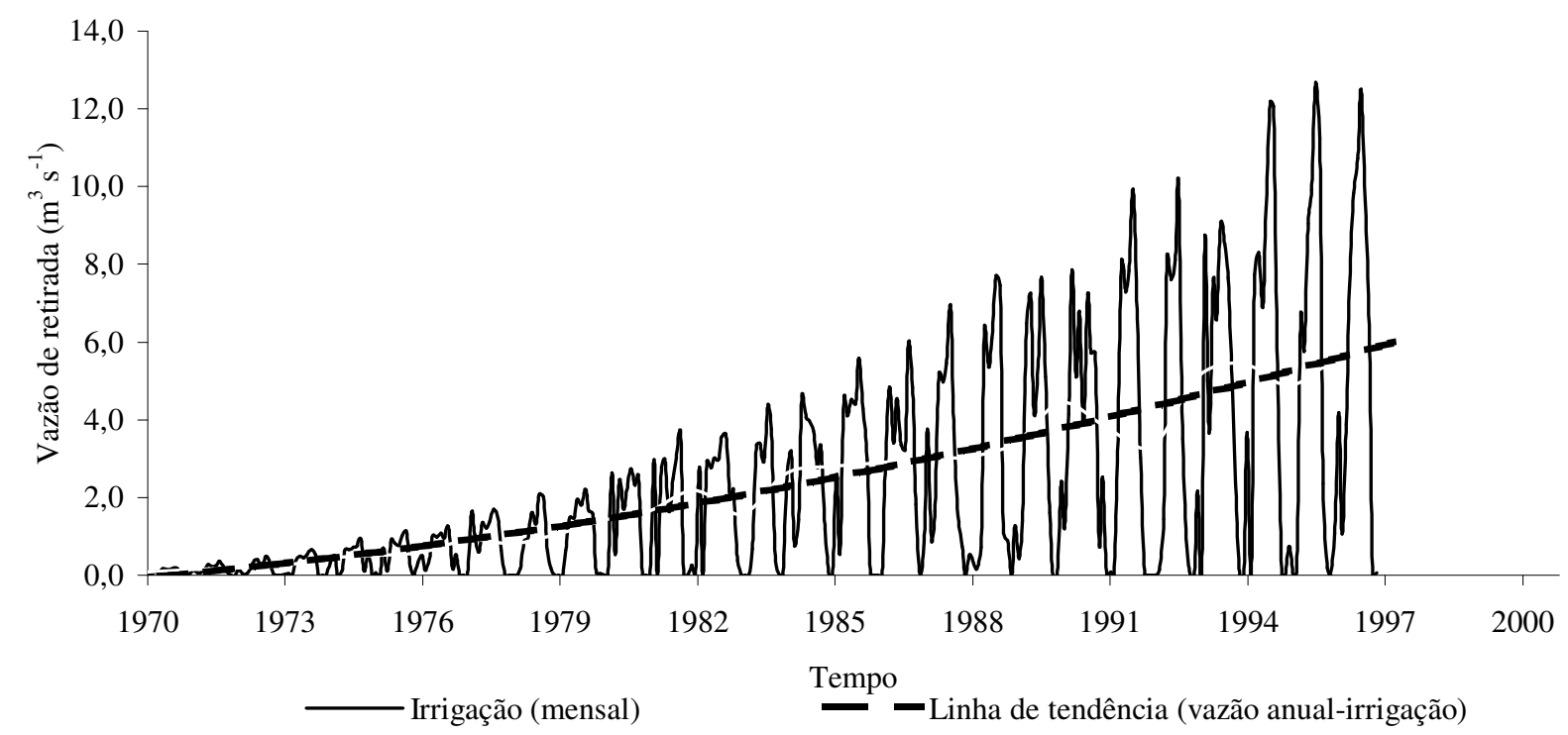

FIGURA 1. Vazões médias mensais e anuais retiradas pela irrigação na bacia do Paracatu, no período de 1970 a 1996.

Nas Figuras 2 e 3, apresenta-se a variação da evapotranspiração da cultura de referência $\left(\mathrm{ET}_{\mathrm{o}}\right)$, do coeficiente da cultura $\left(\mathrm{K}_{\mathrm{c}}\right)$, da evapotranspiração potencial da cultura $\left(\mathrm{ET}_{\mathrm{pc}}\right)$, do 
coeficiente de umidade do solo $\left(\mathrm{K}_{\mathrm{s}}\right)$, da evapotranspiração real da cultura $\left(\mathrm{ET}_{\mathrm{r}}\right)$, da precipitação $(\mathrm{P})$, da precipitação efetiva $\left(\mathrm{P}_{\mathrm{e}}\right)$, da vazão de retirada pela irrigação (Qr), da vazão unitária de retirada pela irrigação (qr) e da quantidade de água necessária paras as culturas irrigadas (Qn), durante o ano de 1996, no município de Unaí, onde esteve concentrada, em 1996, 30\% (109 km²) da área irrigada da bacia. As culturas irrigadas predominantes nesse município foram o feijão (51\% do total irrigado), a soja ( $21 \%$ do total irrigado) e o milho ( $21 \%$ do total irrigado), sendo os valores apresentados nas Figuras 2 e 3, representativos de média ponderada, considerando a área irrigada e o estádio de desenvolvimento de todas as culturas encontradas no campo. Nas Figuras 2 e 3 , a evapotranspiração e as precipitações foram expressas em $\mathrm{mm} \mathrm{d}^{-1}$ com o intuito de melhor comparação entre as variáveis.

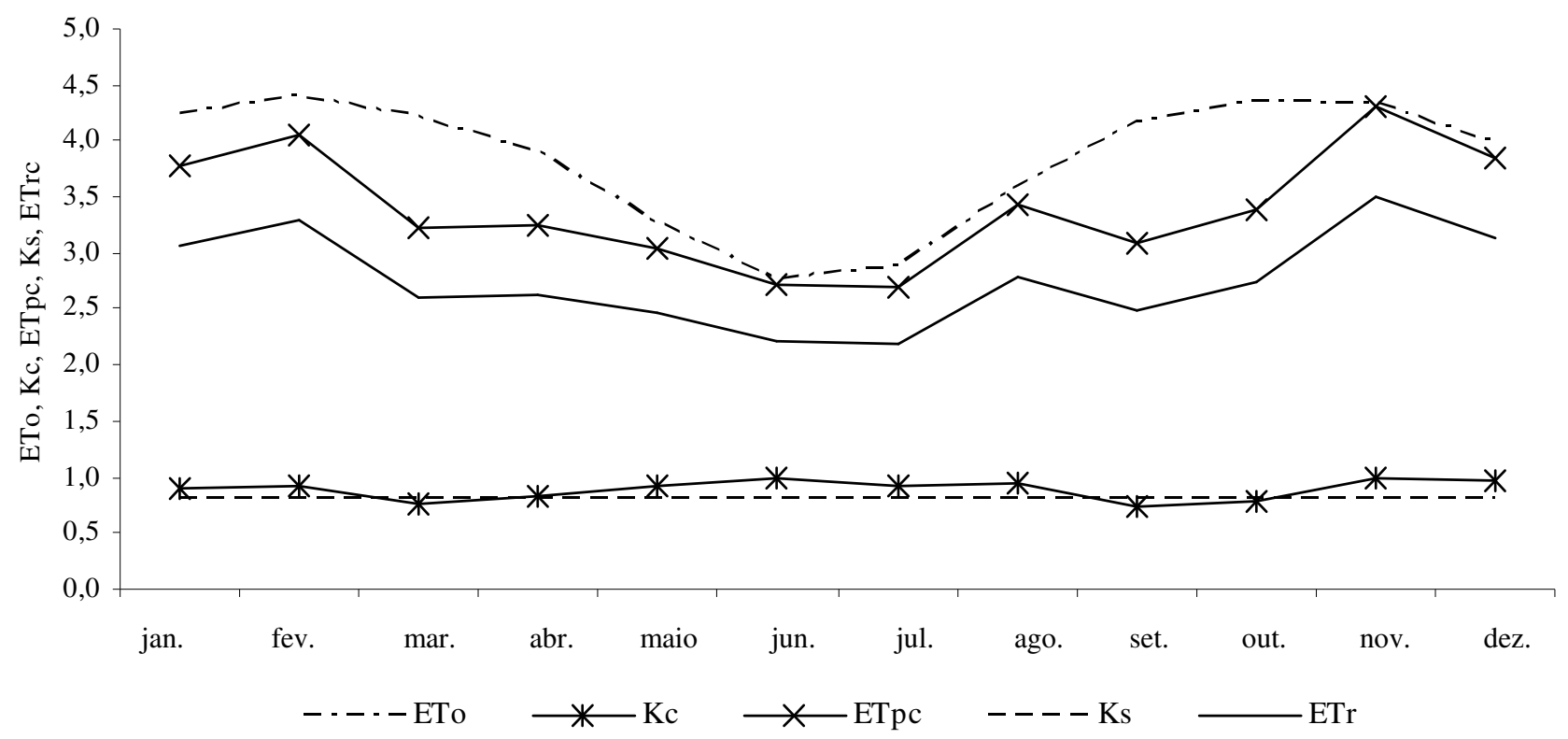

FIGURA 2. Evapotranspiração potencial da cultura de referência $\left(E_{0}-m m d^{-1}\right), K_{c}$, evapotraspiração potencial $\left(\mathrm{ET}_{\mathrm{pc}}-\mathrm{mm} \mathrm{d}^{-1}\right), \mathrm{K}_{\mathrm{s}}$ e evapotraspiração real $\left(\mathrm{ET}_{\mathrm{r}}-\mathrm{mm} \mathrm{d}^{-1}\right)$ durante 1996, no município de Unaí.

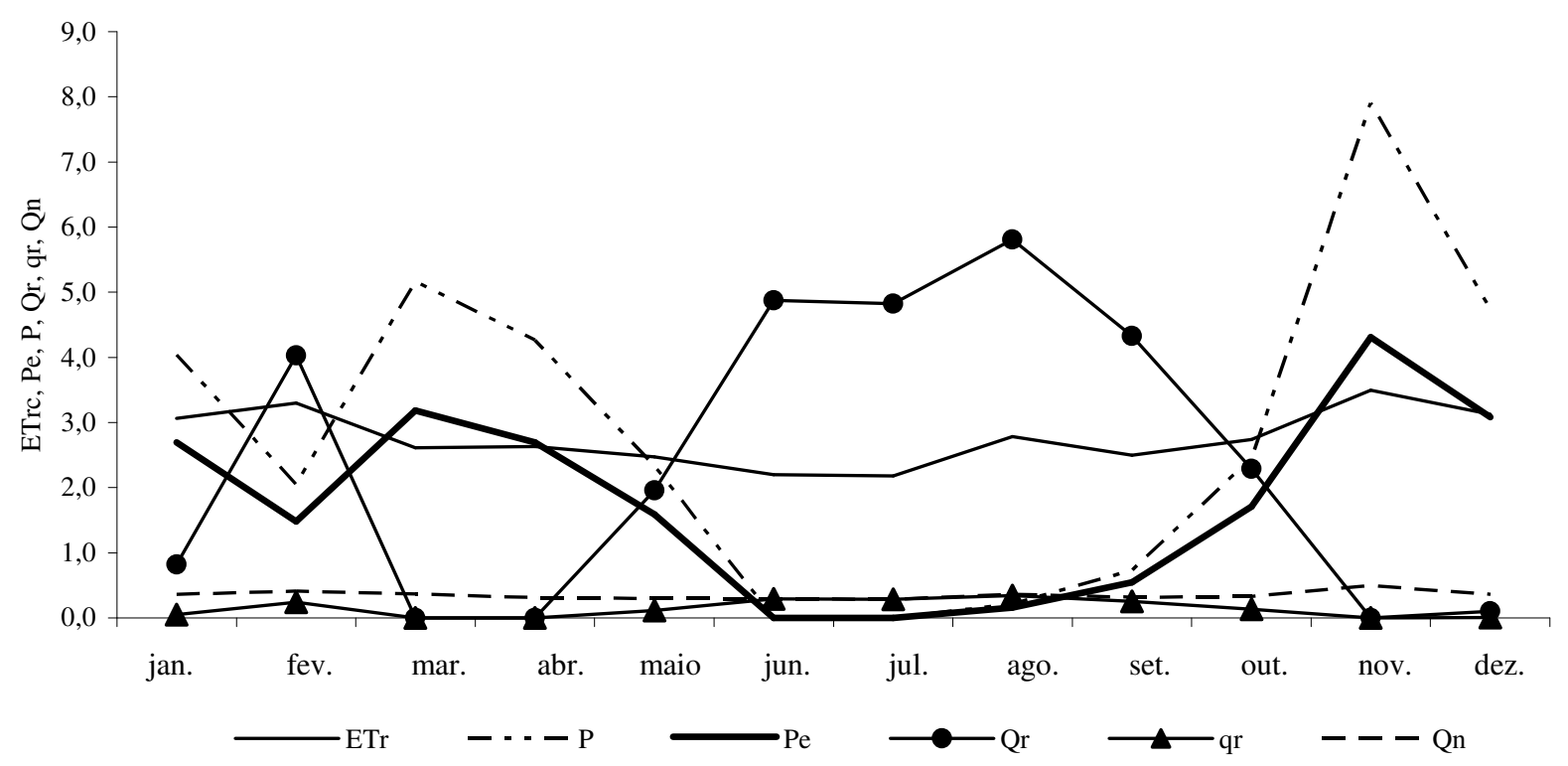

FIGURA 3. Evapotranspiração real $\left(\mathrm{ET}_{\mathrm{r}}-\mathrm{mm} \mathrm{d}^{-1}\right)$, precipitação $\left(\mathrm{P}-\mathrm{mm} \mathrm{d}^{-1}\right)$, precipitação efetiva $\left(\mathrm{P}_{\mathrm{e}}-\mathrm{mm} \mathrm{d}^{-1}\right)$, vazão de retirada pela irrigação $\left(\mathrm{Q}_{\mathrm{r}}-\mathrm{m}^{3} \mathrm{~s}^{-1}\right)$, vazão unitária de retirada pela irrigação $\left(\mathrm{q}_{\mathrm{r}}-\mathrm{L} \mathrm{s}^{-1} \mathrm{ha}^{-1}\right)$ e quantidade de água necessária para as culturas irrigadas $\left(\mathrm{Q}_{\mathrm{n}}-\mathrm{L} \mathrm{s}^{-1} \mathrm{ha}^{-1}\right)$ durante 1996, no município de Unaí. 
A evapotranspiração potencial da cultura de referência, no ano de 1996 , variou de $2,8 \mathrm{~mm} \mathrm{~d}^{-1}$ $\left(82,9 \mathrm{~mm} \mathrm{mês}^{-1}\right)$ no mês de junho, a $4,4 \mathrm{~mm} \mathrm{~d}^{-1}\left(127,6 \mathrm{~mm} \mathrm{mês}^{-1}\right)$ no mês de fevereiro, sendo esses valores semelhantes aos evidenciados no Plano Diretor de Recursos Hídricos da Bacia do Paracatu - PLANPAR (BRASIL, 1996), no qual a evapotranspiração variou de 50 a 80 mm (mínimo), nos meses de junho e julho, a 90 a 163 mm (máximo), nos meses de outubro a março.

Em março, setembro e outubro, os valores de $\mathrm{K}_{\mathrm{c}}$ diminuíram em virtude de esses meses representarem o plantio/colheita das culturas irrigadas, em que os valores de $\mathrm{K}_{\mathrm{c}}$ são mais baixos, uma vez que representam os estágios de desenvolvimento inicial e final da cultura. A evapotranspiração potencial da cultura, obtida pelo produto da evapotranspiração potencial da cultura de referência pelo $\mathrm{K}_{\mathrm{c}}$, refletiu, consequientemente, no comportamento dessas duas variáveis, apresentando maior declínio em relação à evapotranspiração potencial da cultura de referência nos meses em que o $\mathrm{K}_{\mathrm{c}}$ foi menor.

$\mathrm{O}$ valor de $\mathrm{K}_{\mathrm{s}}$ obtido durante todo o ano foi em torno de 0,8 , tendo em vista o fato de as culturas irrigadas predominantes no município estarem associadas ao método de irrigação por aspersão, para o qual o valor de $\mathrm{K}_{\mathrm{s}}$ proposto por RAMOS \& PRUSKI (2003) foi de 0,81 .

A evapotranspiração real da cultura, representada pelo produto da evapotranspiração potencial da cultura pelo coeficiente de umidade do solo, apresentou a mesma tendência de comportamento da evapotranspiração potencial da cultura, entretanto com magnitude de $80 \%$ dessa, variando de 2,18 a $3,30 \mathrm{~mm} \mathrm{~d}^{-1}$.

Na Figura 3, evidencia-se que, em junho e julho, as precipitações foram nulas, sendo essas inferiores a $1 \mathrm{~mm} \mathrm{mês}{ }^{-1}$ também em agosto e setembro. As maiores precipitações ocorreram em novembro (237 mm mês $\left.{ }^{-1}\right)$, março (160 mm mês $\left.{ }^{-1}\right)$, dezembro (147 mm mês $\left.{ }^{-1}\right)$, abril (128 mm mês $\left.{ }^{-1}\right)$ e janeiro (125 mm mês $\left.{ }^{-1}\right)$.

Uma vez que a precipitação efetiva se refere apenas à parte da precipitação utilizada para atender à demanda evapotranspirométrica de culturas, seus valores foram menores que os observados na precipitação real. Nos meses de menores precipitações (junho a setembro), a precipitação efetiva apresentou valores bastante baixos, próximos aos da precipitação real. À medida que a precipitação real aumenta, a precipitação efetiva também aumenta, embora a diferença entre essas duas variáveis também aumente. Assim, no mês de maior precipitação (novembro), $129 \mathrm{~mm}^{\text {mês }}{ }^{-1}$ tornam-se efetivamente disponíveis para a cultura, sendo $108 \mathrm{~mm}$ mês ${ }^{-1}$ perdidos do ponto de vista de utilização pelas culturas irrigadas.

Conforme também se pode evidenciar na Figura 3, a maior vazão de retirada pela irrigação foi observada em agosto, mês em que, embora a evapotranspiração real da cultura não tenha sido máxima nem a precipitação efetiva tenha sido mínima, ocorreu a maior diferença entre essas duas variáveis, ocasionando vazão de retirada de $5,8 \mathrm{~m}^{3} \mathrm{~s}^{-1}$ (vazão unitária de $0,34 \mathrm{~L} \mathrm{~s}^{-1} \mathrm{ha}^{-1}$ ). Já em meses como novembro (mesmo a evapotranspiração real da cultura sendo máxima), março, abril e dezembro, a precipitação efetiva superou a evapotranspiração real da cultura, fazendo com que a vazão retirada para a irrigação fosse nula e que a vazão unitária média em Unaí, em 1996, fosse de $0,14 \mathrm{~L} \mathrm{~s}^{-1} \mathrm{ha}^{-1}$.

A vazão máxima de retirada pela irrigação na bacia do Paracatu foi $12,49 \mathrm{~m}^{3} \mathrm{~s}^{-1}$, correspondente ao mês de agosto, e uma vazão unitária máxima de retirada pela irrigação de $0,34 \mathrm{~L} \mathrm{~s}^{-1} \mathrm{ha}^{-1}$, enquanto a vazão unitária média anual de retirada pela irrigação foi de $0,15 \mathrm{~L} \mathrm{~s}^{-1} \mathrm{ha}^{-1}$, valores bem abaixo daqueles normalmente utilizados como base de referência para $\mathrm{o}$ projeto de sistemas de irrigação ou, mesmo, para calcular a quantidade de água demandada pela agricultura irrigada.

Os valores da quantidade de água necessária para atender à demanda das culturas irrigadas variaram de $0,29 \mathrm{~L} \mathrm{~s}^{-1} \mathrm{ha}^{-1}$ (julho) a $0,50 \mathrm{~L} \mathrm{~s}^{-1} \mathrm{ha}^{-1}$ (novembro), e o valor médio de $0,35 \mathrm{~L} \mathrm{~s}^{-1} \mathrm{ha}^{-1}$ foi 2,5 vezes maior ao correspondente à vazão unitária de retirada média anual. 


\section{CONCLUSÕES}

A vazão média anual retirada pela irrigação na bacia do Paracatu, no ano de 1996, foi de $0,15 \mathrm{~L} \mathrm{~s}^{-1} \mathrm{ha}^{-1}$, sendo a vazão média retirada no mês de maior demanda de $0,34 \mathrm{~L} \mathrm{~s}^{-1} \mathrm{ha}^{-1}$.

A quantidade média de água necessária para atender à demanda das culturas irrigadas na bacia do Paracatu foi de $0,35 \mathrm{~L} \mathrm{~s}^{-1} \mathrm{ha}^{-1}$, sendo o valor correspondente ao mês de maior demanda evapotranspirométrica de $0,50 \mathrm{~L} \mathrm{~s}^{-1} \mathrm{ha}^{-1}$.

\section{REFERÊNCIAS}

ALLEN, R.G.; PEREIRA, L.S.; RAES, D.; SMITH, M. Crop evapotranspiration: guidelines for computing crop water requirements. Roma: FAO, 1998. 328 p. (FAO Irrigation and Drainage Paper, 56).

ANA. AGÊNCIA NACIONAL DE ÁGUAS. A evolução da gestão dos recursos hídricos no Brasil. Brasília, 2002. 64 p. Edição Comemorativa do Dia Mundial da Água.

BERNARDO, S.; SOARES, A.A.; MANTOVANI, E.C. Manual de irrigação. 7.ed. Viçosa: UFV, 2005. $611 \mathrm{p}$.

BRASIL. Ministério do Meio Ambiente. Plano Diretor de Recursos Hídricos da Bacia do Rio Paracatu. Brasília: PLANPAR, 1996. v.1, t.1. CD-ROM.

DOORENBOS, J.; PRUITT, W.O. Las necessidades de agua de los cultivos. Roma: FAO Irrigation and Drainage, 1977. 144 p. (Paper, 24).

FERREIRA, A.N.P.; ARAÚJO NETO. Os comitês de bacias hidrográficas e os conflitos pelo uso da água no Distrito Federal. Disponível em:

<www.unicamp.br/nepo/principal/eventos/agua/ferreira pdf>. Acesso em: 12 dez. 2004.

IBGE. INSTITUTO BRASILEIRO DE GEOGRAFIA E ESTATÍSTICA. Censo agropecuário, 1996. 1 CD-ROM.

PEREIRA, S.B. Evaporação no lago Sobradinho e disponibilidade hídrica no Rio São Francisco. 2004. 103 f. Tese (Doutorado em Recursos Hídricos e Ambientais) - Universidade Federal de Viçosa, Departamento de Engenharia Agrícola, Viçosa, 2004.

RAMOS, M.M.; PRUSKI, F.F. Subprojeto 4.3 - Quantificação e análise da eficiência do uso da água pelo setor agrícola na bacia do São Francisco. In: __. Projeto gerenciamento integrado das atividades desenvolvidas em terra na bacia do São Francisco. Viçosa, MG: UFV;

ANA/GEF/PNUMA/OEA, 2003. 190 p. Relatório Final.

TUCCI, C.E.M.; HESPANHOL, I.; CORDEIRO NETTO, O.M. Gestão de água no Brasil. Brasília: UNESCO, 2001. 156 p.

UNESCO. UNITED NATIONS EDUCATIONAL, SCIENTIFIC AND CULTURAL ORGANIZATION. Water for people, water for life: un world water development report. Paris, 2003. 34 p. 